\title{
Neuromarkers for in-hospital mortality prediction. Are they valuable?
}

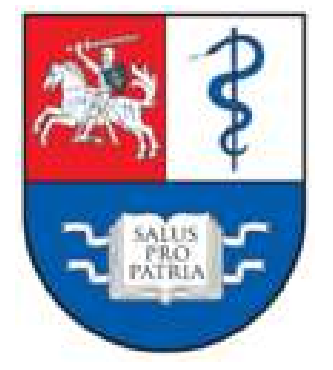

\author{
A. Vilke $^{1,2}$, D. Bilskiene ${ }^{2}$, V. Traskaite ${ }^{2}$, D. Ranceviene ${ }^{2}$, A. Macas ${ }^{2}$ \\ ${ }^{1}$ Lithuanian University of Health Sciences, Department of \\ Anesthesiology, Neuroscience Institute, Kaunas, Lithuania \\ 2 Lithuanian University of Health Sciences, Dept. of Anesthesiology, \\ Kaunas, Lithuania
}

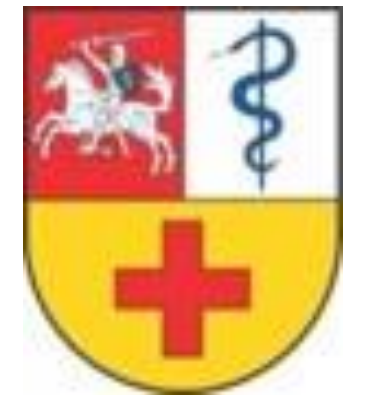

\section{Background and Aim of the Study}

Traumatic brain injury (TBI) is serious and often lethal condition so predicting its outcomes can be really beneficial. Investigation of neuromarkers is simple but not widely used method of outcome prediction. The aim of this study was to compare serum S10oB and NSE values for in-hospital mortality prediction after TBI.

\section{Materials and Methods}

A prospective study took place in Anesthesiology clinic of Lithuanian University of Health Sciences (LUHS) Kaunas Clinics. Serum of 46 patients with severe TBI was investigated for neuromarkers S100B and NSE at hospital admission. The same investigation was repeated 24,48 and 72 hours after the admission in order to evaluate the value for in-hospital mortality prediction. Outcomes were assessed and compared to specific values using nonparametric statistical tests. All 4 measurements were obligatory for inclusion to the study. Level of $p \leq 0.05$ was assumed as statistically significant. Approval of Regional bioethics committee was obtained before study initiation.

\section{Results}

46 patients were involved in the study. The average age was $55.33 \pm 16.8$ years and there was no significant difference between women and men, however the number of men were higher than women, 35 and 11 respectively. The median of each test was used to evaluate if the specific value had an impact for in-hospital mortality. The medians of S100B were 14.98 pg/ml [7.21;67.66], 12.69 $\mathrm{pg} / \mathrm{ml}$ [7.21; 66.88], $10.3 \mathrm{pg} / \mathrm{ml}$ [7.21;40.77] and $9.7 \mathrm{pg} / \mathrm{ml}$ [0.9; 12.69] at hospital admission, after 24,48 and 72 hours respectively. Only $12.69 \mathrm{pg} / \mathrm{ml}$ and $10.3 \mathrm{pg} / \mathrm{ml}$ differed statistically significantly but had no impact on increasing the risk of in-hospital mortality. The medians of NSE were $9.72 \mu \mathrm{g} / \mathrm{l}[3.93 ; 21.54], 7.56 \mu \mathrm{g} / \mathrm{l}[3.99 ; 14.65], 6.24 \mu \mathrm{g} / \mathrm{l}[3.15 ; 17.23], 5.65 \mu \mathrm{g} / \mathrm{l}[3.08 ; 15.87]$ at hospital admission, after 24,48 and 72 hours respectively. The values of $7.56 \mu \mathrm{g} / \mathrm{l}$ and $6.24 \mu \mathrm{g} / \mathrm{l}$ had a statistically significant difference and increased the risk of in-hospital mortality 4.0 and 9.35 times respectively. The measurement of both neuromarkers at hospital admission and after 72 hours had no significant difference while the second measurement after 24 hours and the third measurement after 48 hours of both markers were statistically significant.

Figure 1. Maximum values of $\mathrm{S} 100 \mathrm{~B}$

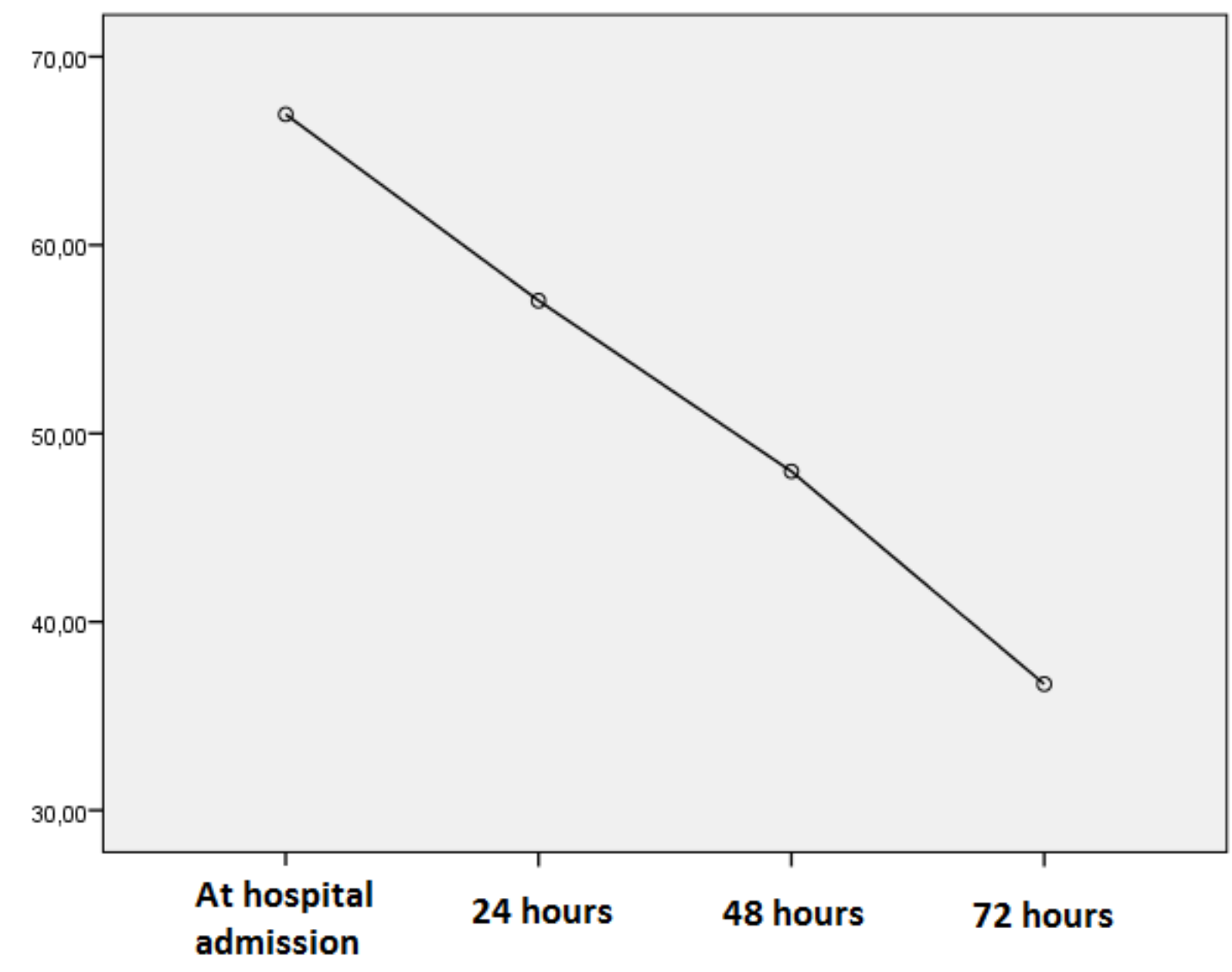

Figure 2. Maximum values of NSE

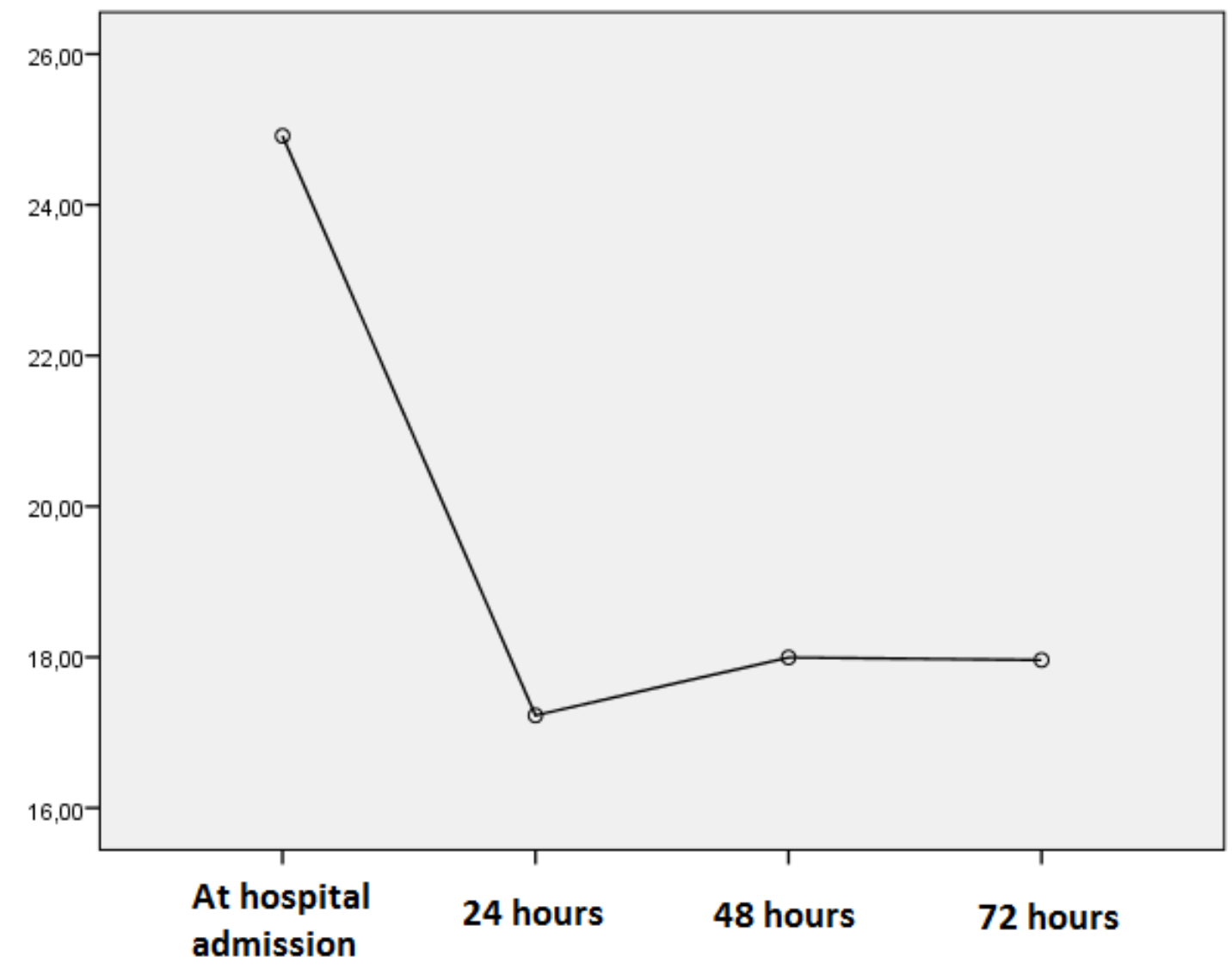

\section{Conclusion}

Both S100B and NSE can be predictors of in-hospital mortality for patients with severe TBI. However, the time of neuromarkers investigation is important as only after 24 and 48 hours the statistical significance was found. Moreover, it can be assumed that NSE is slightly more valuable than S100B for in-hospital mortality prediction in severe traumatic brain injury. 